\title{
Producción de biohidrógeno a partir de residuos mediante fermentación oscura: una revisión crítica (1993-2011)
}

\author{
Biohydrogen production from wastes via dark fermentation: A critical review \\ (1993-2011)
}

\author{
Sergio Andrés Blanco Londoño ${ }^{1} \quad$ Tatiana Rodríguez Chaparro ${ }^{1}$ \\ Recibido 22 de marzo de 2012, aceptado 13 de agosto de 2012 \\ Received: March 22, 2012 Accepted: August 13, 2012
}

\begin{abstract}
RESUMEN
El hidrógeno es una energía atractiva debido a su alto contenido energético y combustión amigable. Entre los diferentes mecanismos existentes para la producción de hidrógeno, la fermentación oscura es uno de los más interesantes debido a que se aprovechan residuos como materia prima. Actualmente, la investigación en hidrógeno se encuentra en desarrollo, sin embargo, los resultados no han sido concluyentes, existiendo aún un vacío en los factores que se deben tener en cuenta y sobre todo no se ha llegado al nivel máximo de producción. En este sentido, este trabajo pretende, por medio de una revisión crítica de estudios realizados en el periodo 1993-2011, mostrar los factores más estudiados, configuraciones más empleadas y los principales resultados en este tema. Con base en esto, se encontró no sólo la necesidad de optimizar los factores que influyen en la producción, sino también la necesidad de incrementar la realización de estudios en escala real y régimen continuo.
\end{abstract}

Palabras clave: Biohidrógeno, energía renovable, fermentación oscura, optimización, residuos.

\section{ABSTRACT}

Hydrogen is an attractive energy source due to its high energy content and friendly combustion. Among the various mechanisms for hydrogen production, dark fermentation is one of the most interesting, because it uses the wastes as feedstock. The research on hydrogen production is to date in study, but the results are not yet conclusive. In this sense, this paper aims to do a critical review between 1993 and 2011 to show the most studied factors, the configurations most employed and the main results on this topic. Our findings showed the need, not only to optimize the factors that influence the production, but also to do more studies on real scale and in continuous flow.

Keywords: Biohydrogen, renewable energy, dark fermentation, optimization, waste.

\section{INTRODUCCIÓN}

El hidrógeno es una alternativa prometedora para reemplazar los combustibles convencionales porque es renovable y limpio y produce durante su combustión únicamente vapor de agua y energía. Además, posee el mayor contenido energético por unidad de peso, $122-142 \mathrm{~kJ} / \mathrm{g}$, comparado con cualquier combustible conocido [1-2]. Sin embargo, el $\mathrm{H}_{2}$ no está disponible en forma natural como los combustibles fósiles, por lo tanto el mayor interés está dado en la forma de producirlo y especialmente a partir de materiales renovables tales como la biomasa o el agua.

Actualmente, el $40 \%$ del gas $\mathrm{H}_{2}$ se obtiene de la oxidación catalítica de gases naturales, el $30 \%$ de

1 Laboratorio de Saneamiento. Programa de Ingeniería Civil. Universidad Militar Nueva Granada. C.P.: 110111. Bogotá, Colombia. E-mail: sergio.blanco@unimilitar.edu.co; adela.rodriguez@unimilitar.edu.co 
metales pesados y nafta, el 18\% de carbón, el $4 \%$ de la electrólisis y cerca del $1 \%$ de biomasa [2]. Entre las formas de obtención de hidrógeno no está disponible en forma natural como las anteriormente mencionadas; la producción biológica a partir de biomasa presenta un mayor interés por ser potencialmente una forma de producción inagotable.

Los estudios en la producción de hidrógeno biológico se han enfocado principalmente en la biofotólisis del agua empleando algas y cianobacterias, la fotofermentación de compuestos orgánicos por bacterias fotosintéticas y la fermentación oscura de compuestos orgánicos ricos en carbohidratos mediante bacterias anaerobias; en la Figura 1 se muestra una breve comparación de estos procesos.

La obtención de hidrógeno por procesos fermentativos o fermentación oscura aparenta ser la más favorable puesto que se puede generar de forma continua y a altas tasas de producción comparado con los otros procesos biológicos [3-4]. Además, si se utiliza materia orgánica de residuos es posible obtener un producto con valor agregado a partir del tratamiento de un desecho. Los estudios en relación con la producción de hidrógeno vía fermentación oscura no presentan resultados conclusivos.

De acuerdo con lo anterior, en este artículo se pretende realizar una revisión crítica de la producción de biohidrógeno mediante la fermentación oscura de residuos. Igualmente, se explica todo el proceso de obtención de este gas comenzado por la fermentación oscura, pasando por las rutas metabólicas hasta los factores que afectan la producción. Adicionalmente, se ha incluido una lista de diferentes estudios realizados y una discusión de estos para evidenciar cuáles han sido las condiciones experimentales más empleadas y qué resultados se han obtenido. Todo esto con el objetivo de presentar el estado del arte de la producción de biohidrógeno por fermentación oscura y con ello plantear retos y perspectivas futuras alrededor de este tema.

\section{Fermentación oscura}

La generación de biohidrógeno a través de la fermentación oscura se logra principalmente por bacterias estrictamente anaerobias o anaerobias facultativas. En general, son especies del género Clostridium formadoras de esporas, facultativas de los géneros Enterobacter y Bacillus [5-9], algunas bacterias termofílicas [10-12] y acidogénicas anaerobias provenientes de lodos $[5,13]$.

Usualmente, los monosacáridos son la principal fuente de carbono donde se destaca particularmente la glucosa seguido de la xilosa, el almidón, la celulosa y otras fuentes que pueden ser generadas a partir de la hidrólisis de polisacáridos, proteínas y lípidos, por esta razón la reacción de biotransformación de la glucosa a ácido acético, $\mathrm{H}_{2}$ y $\mathrm{CO}_{2}$ (ecuación ((1), es la ecuación ampliamente aceptada como referencia para la estimación de la producción teórica del hidrógeno fermentativo $[1,14]$.

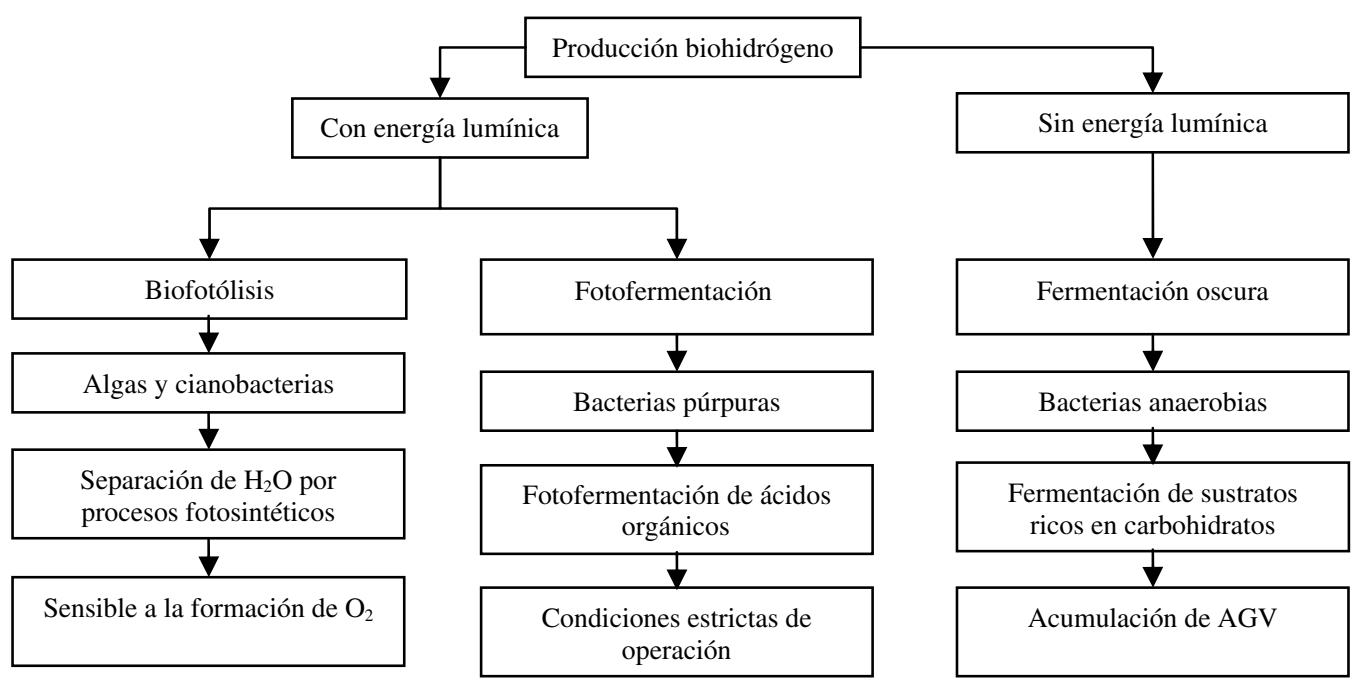

Figura 1. Comparación de los diferentes procesos de producción de biohidrógeno. 


$$
\begin{aligned}
& \mathrm{C}_{6} \mathrm{H}_{12} \mathrm{O}_{6}+2 \mathrm{H}_{2} \mathrm{O} \rightarrow 2 \mathrm{CH}_{3} \mathrm{COOH}+4 \mathrm{H}_{2}+2 \mathrm{CO}_{2} \\
& \Delta \mathrm{G}^{\mathrm{o}}=-206 \mathrm{~kJ} \mathrm{~mol}^{-1}
\end{aligned}
$$

De acuerdo con esta reacción la producción máxima teórica de biohidrógeno a partir de la fermentación de la glucosa es de 4 moles de $\mathrm{H}_{2}$ por mol de glucosa consumida cuando el ácido acético es el único ácido graso volátil (AGV) producido. En cuanto a la energía libre de Gibbs el valor negativo indica que en la reacción se forman productos espontáneamente sin necesidad de requerimientos energéticos externos.

La máxima producción teórica de hidrógeno también se puede lograr en un proceso de dos etapas mediante la fermentación de la glucosa a acetato y formiato de acuerdo con las reacciones $2 \mathrm{a}$ y $2 \mathrm{~b}$ [15].

$$
\begin{gathered}
\mathrm{C}_{6} \mathrm{H}_{12} \mathrm{O}_{6}+2 \mathrm{H}_{2} \mathrm{O} \rightarrow 2 \mathrm{CH}_{3} \mathrm{COO}^{-}+ \\
2 \mathrm{HCOO}^{-}+4 \mathrm{H}^{+}+2 \mathrm{H}_{2} \\
\Delta \mathrm{G}^{\mathrm{o}}=-209,1 \mathrm{~kJ} \mathrm{~mol}^{-1} \\
2 \mathrm{HCOOH} \rightarrow 2 \mathrm{CO}_{2}+2 \mathrm{H}_{2} \\
\Delta \mathrm{G}^{\mathrm{o}}=-6 \mathrm{~kJ} \mathrm{~mol}^{-1}
\end{gathered}
$$

Sin embargo, en la práctica se obtienen bajas producciones de $\mathrm{H}_{2}$ debido a que parte de la glucosa es empleada por los microorganismos para su sustento $\mathrm{y}$ crecimiento microbiano. Adicionalmente, cuando la transformación genera como subproducto ácido butírico se producen 2 moles de $\mathrm{H}_{2}$ por mol de glucosa y si se genera ácido propiónico se produce un consumo de $1 \mathrm{~mol} \mathrm{de} \mathrm{H}_{2}$ por mol de ácido propiónico generado [1]. La fermentación de ácido láctico y etanol no genera consumo ni producción de $\mathrm{H}_{2}$. Si se produce ácido acético y butírico al mismo tiempo como subproducto en la fermentación se generan 2,5 moles $\mathrm{H}_{2}$ por mol de glucosa.

La presencia de consumidoras de $\mathrm{H}_{2}$ tales como las bacterias homoacetogénicas, metanogénicas [15] y reductoras de nitratos y sulfatos son otro factor que reduce la producción de hidrógeno. Otros factores importantes que afectan el desempeño de la fermentación oscura están relacionados con las condiciones de operación tales como $\mathrm{pH}$, tiempo de retención hidráulico, nutrientes, temperatura, concentración del sustrato, inóculo y tipo de sustrato.

La cantidad de hidrógeno obtenido por procesos fermentativos se puede cuantificar en términos de rendimiento y tasa. El rendimiento se define como la cantidad de $\mathrm{H}_{2}$ producido por cantidad de sustrato consumido y se expresa en unidades de mol $\mathrm{H}_{2} /$ mol de glucosa. La tasa de producción de hidrógeno (TPH) se define como la cantidad de $\mathrm{H}_{2}$ $(\mathrm{ml})$ producido por unidad de tiempo y por unidad de volumen de reactor (tasa volumétrica) o por unidad de biomasa (tasa específica) [1].

Es importante mencionar que es posible ajustar matemáticamente la producción de hidrógeno por fermentación oscura mediante la ecuación modificada de Gompertz (ecuación (3)), la cual es un modelo adaptado para describir el progreso acumulativo de producción de $\mathrm{H}_{2}$ en un experimento batch.

$$
H=H_{\text {máx }} \exp \left\{-\exp \left[\frac{R_{\text {máx }} \times e}{H_{\text {máx }}(\lambda-t)}+1\right]\right\}
$$

donde $\mathrm{H}$ corresponde a la producción acumulada de $\mathrm{H}_{2}(\mathrm{ml}), \mathrm{H}_{\text {máx }}$ a la producción acumulada máxima de $\mathrm{H}_{2}$ en (ml), $\mathrm{R}_{\text {máx }}$ la tasa de producción máxima de $\mathrm{H}_{2}$ en $(\mathrm{ml} / \mathrm{h})$, t el tiempo del cultivo en (h) y $\lambda$ el tiempo de retardo en (h) requerido para comenzar la evolución del $\mathrm{H}_{2}$. Esta ecuación ha sido empleada por diferentes autores [10,16-18] con muy buenos ajustes $r^{2}>0,90$, donde se ha querido correlacionar resultados experimentales con un modelo matemático de tipo predictivo.

\section{Rutas de producción de hidrógeno fermentativo}

En ambientes anóxicos, los protones pueden actuar como un aceptor de electrones en presencia de la enzima hidrogenasa, la cual es clave en el proceso de catalización para la producción de $\mathrm{H}_{2}$ [1-2] . En estas condiciones las bacterias anaerobias sin requerimientos de energía lumínica fermentan sustratos ricos en carbohidratos. En este proceso interactúan diversas clases de microorganismos, las cuales convierten la materia orgánica en otros compuestos, incluido el hidrógeno, y en nuevas células bacterianas. El proceso se divide en varias rutas metabólicas con la participación de diferentes grupos microbianos, cada uno con un comportamiento fisiológico distinto.

La formación de hidrógeno comienza con la hidrólisis de materiales particulados complejos en materiales disueltos más simples, entre ellos la glucosa, por bacterias fermentativas hidrolíticas. En este punto se desarrolla una serie de reacciones enzimáticas donde la glucosa es convertida a través de la vía 
metabólica de la glucólisis también conocida como vía Embden-Meyer-Parnas (EMP) al ácido pirúvico, ecuación (4), a través de la cual 2 moles de hidrógeno pueden ser generados durante la regeneración del $\mathrm{NADH}\left(\mathrm{NADH}+\mathrm{H}^{+} \rightarrow \mathrm{NAD}^{+}+\mathrm{H}_{2}\right)[14,19]$.

$$
\begin{aligned}
& \mathrm{C}_{6} \mathrm{H}_{12} \mathrm{O}_{6}+2 \mathrm{NAD}^{+} \rightarrow 2 \mathrm{CH}_{3} \mathrm{COCOO}^{-}+ \\
& 4 \mathrm{H}^{+}+2 \mathrm{NADH} \\
& \Delta \mathrm{G}^{\mathrm{o}}=-112,1 \mathrm{~kJ} \mathrm{~mol}^{-1}
\end{aligned}
$$

A continuación, el ácido pirúvico sufre un proceso de descarboxilación oxidativa por la coenzima acetilCoA que dependiendo del sistema enzimático que tengan los microorganismos puede ser metabolizada en acetato, butirato o formiato de los cuales se generan entre 2 o 4 moles de $\mathrm{H}_{2} /$ mol de glucosa consumida [15]. De esta manera el acetil-CoA se puede generar a través de dos reacciones, ecuación (5) o (6).

$$
\begin{gathered}
\text { Piruvato }+\mathrm{CoA}+\text { Fdox } \leftrightarrow \text { acetil-CoA }+ \\
\mathrm{CO}_{2}+\text { Fdred } \\
\Delta \mathrm{G}^{\mathrm{o}}=-19,2 \mathrm{~kJ} \mathrm{~mol}^{-1} \\
\text { Piruvato }+\mathrm{CoA} \leftrightarrow \text { acetil-CoA }+ \text { formiato } \\
\Delta \mathrm{G}^{\mathrm{O}}=-16,3 \mathrm{~kJ} \mathrm{~mol}^{-1}
\end{gathered}
$$

La reacción de la Ecuación (5) es catalizada mediante la enzima piruvato-ferredoxinoxidorreductasa, donde el ferredoxín es la coenzima que actúa como receptor de electrones [20]. El acetil-CoA puede además ser metabolizado a acetato (Figura 2a), o a butirato (Figura 2b), y en los dos casos de la reoxidación de cada mol de ferredoxín se genera un mol de $\mathrm{H}_{2}$ con la ayuda de la enzima hidrogenasa.

Si el acetato es el producto final, se genera un mol extra de $\mathrm{H}_{2}$ de la reducción de cada mol de NADH a $\mathrm{NAD}^{+}$generando de esta manera una producción de $\mathrm{H}_{2}$ total de 4 moles/mol de glucosa consumida. Si el butirato es el producto final, el NADH es empleado para la oxidación del acetil-CoA a butirato, por lo tanto la producción de $\mathrm{H}_{2}$ será de 2 moles/mol de glucosa consumida. Dependiendo de las condiciones de cultivo así como del tipo de microorganismos, se puede generar simultáneamente acetato y butirato produciendo entre 2 y 4 moles de $\mathrm{H}_{2}$.

La otra manera de generación de acetil-CoA es como se muestra en la reacción de la Ecuación 6, la cual conduce a la formación de formiato [14]; la reacción que se presenta en la Figura 3 es catalizada por la enzima piruvato formiato liasa, donde se obtienen 2 moles de $\mathrm{H}_{2}$ por mol de glucosa consumida.

\section{Factores que afectan la producción de biohidrógeno}

La producción de hidrógeno depende de varios factores, los cuales están asociados con condiciones ambientales, operacionales y químicas. Estos factores han sido evaluados por diferentes investigadores con el objetivo de obtener la máxima producción de 4 moles de $\mathrm{H}_{2}$ por mol de glucosa. En esta sección se tratará cada uno de ellos explicando cómo afectan la producción de biohidrógeno.
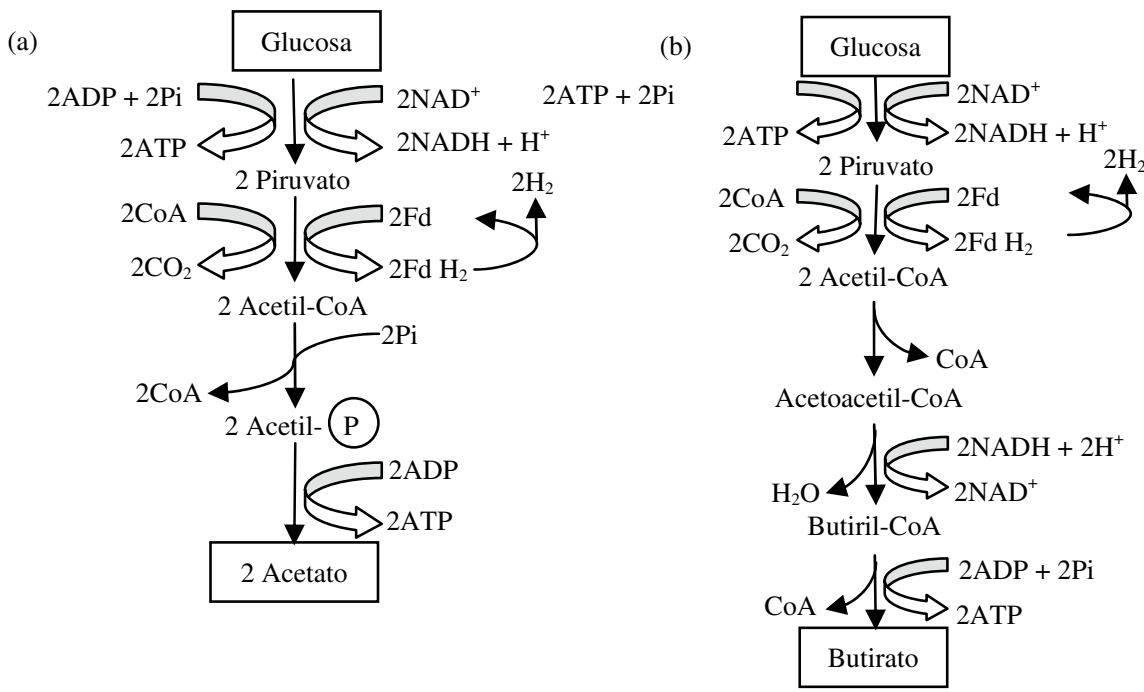

Figura 2. Generación de hidrógeno con producción de acetato (a) y butirato (b) a través de la ruta de la glucólisis. Adaptado de [14]. 


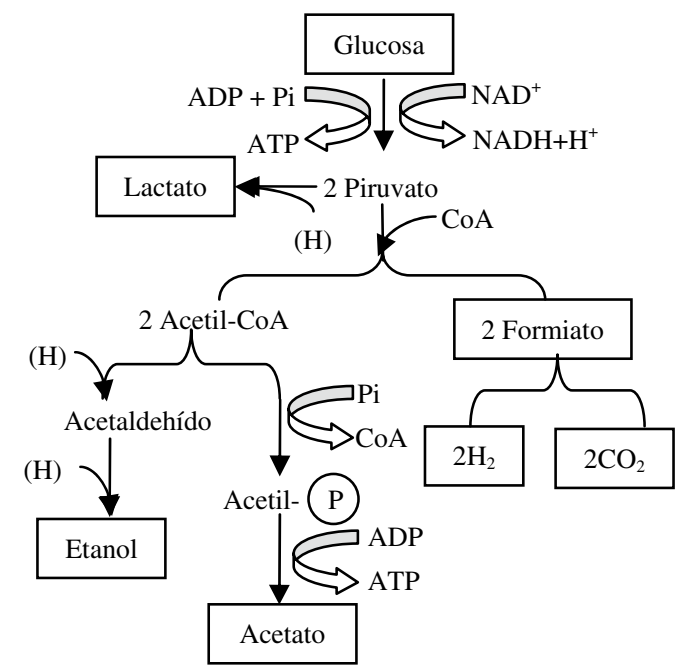

Figura 3. Generación de hidrógeno con producción simultánea de acetato, etanol, lactato y formiato a través de la ruta de la glucólisis. Adaptado de [14].

\section{Inóculo}

Para la obtención de $\mathrm{H}_{2}$ se han empleado bacterias en cultivos puros y mixtos como inóculos que para el primer caso en su mayoría corresponden a especies del género Clostridium y Enterobacter [3, 21]. Los organismos de las diferentes especies del género Clostridium son bacilos gram-positivos, estrictamente anaerobios y formadores de esporas, mientras las Enterobacter son bacterias bacilos gram-negativas y anaerobias facultativas [21]. La mayoría de los estudios para la obtención de $\mathrm{H}_{2}$ se han realizado con cultivos puros, en régimen batch y empleando glucosa como sustrato $[2,21]$.

Actualmente, los cultivos mixtos de bacterias de lodos anaerobios, lodos de plantas de tratamiento, compost y el suelo se han empleado como inóculo para la producción de $\mathrm{H}_{2}$ [22], debido a que existe una amplia fuente de alimentos que los contienen y son potencialmente más resistentes a cambios en las condiciones ambientales en relación con los cultivos puros. Sin embargo, en la producción de $\mathrm{H}_{2}$ empleando cultivos mixtos, el $\mathrm{H}_{2}$ producido puede ser consumido. Por esta razón, para proteger las bacterias productoras de $\mathrm{H}_{2}$, el inóculo es pretratado empleando métodos tales como: choque térmico, acidificación, alcalinidad, congelación y descongelación, aireación y adición de cloroformo, los cuales inactivan la actividad bacteriana de las bacterias consumidoras de $\mathrm{H}_{2}$ para impedir que estas proliferen [23].

\section{pH del cultivo}

$\mathrm{El} \mathrm{pH}$ es un factor importante que influye en la actividad de las bacterias productoras de $\mathrm{H}_{2}$, porque afecta la actividad de la hidrogenasa así como las rutas metabólicas [2-3, 21]. Estudios comparativos con respecto al efecto del $\mathrm{pH}$ en la producción de $\mathrm{H}_{2}$ han mostrado que el rango de $\mathrm{pH}$ óptimo para lograr la máxima producción de $\mathrm{H}_{2}$ está entre 4,5 y 6,0 [3].

\section{Sustrato}

Para la producción de $\mathrm{H}_{2}$ se han empleado diferentes clases de sustratos. La glucosa, sacarosa y el almidón son los que más se han empleado como sustrato [21]. En muy pocos estudios se han utilizado residuos orgánicos como sustrato para la producción de $\mathrm{H}_{2}$ [2].

Para la producción de $\mathrm{H}_{2}$ no es ideal emplear sustratos con estructuras moleculares complejas debido a que estos son difíciles de asimilar por los microorganismos, sin embargo después de emplear un pretratamiento con algunos métodos estos sustratos pueden ser fácilmente asimilados por las bacterias productoras de $\mathrm{H}_{2}$ [21].

Los pretratamientos más conocidos para la degradación de sustratos difíciles son la ultrasonificación, acidificación, el congelamiento y descongelamiento, esterilización y las microondas.

\section{Temperatura}

La temperatura es un factor que influye en la actividad de las bacterias productoras de $\mathrm{H}_{2}$ y en la producción de $\mathrm{H}_{2}$ fermentativo, siendo un parámetro de tipo selectivo pues afecta la tasa de crecimiento y la ruta metabólica de los microorganismos. Las bacterias son capaces de producir $\mathrm{H}_{2}$ en rangos de temperatura que van desde 15 hasta $85^{\circ} \mathrm{C}$, en rango mesofílico $\left(25-30{ }^{\circ} \mathrm{C}\right)$, termofílico $\left(40-65{ }^{\circ} \mathrm{C}\right) \mathrm{e}$ hipertermofílico $\left(>80^{\circ} \mathrm{C}\right)$.

\section{Nutrientes}

En los procesos fermentativos para producción de $\mathrm{H}_{2}$ el nitrógeno, los fosfatos y algunos iones metálicos son importantes para el crecimiento celular de las bacterias productoras de $\mathrm{H}_{2}$.

El nitrógeno es un componente de las proteínas, ácidos nucleicos y enzimas, por lo tanto una concentración 
de nitrógeno apropiada favorece el crecimiento de las bacterias productoras de hidrógeno y la producción de $\mathrm{H}_{2}$ fermentativo [24].

En relación con los fosfatos estos son necesarios para la producción de $\mathrm{H}_{2}$ debido a su valor nutricional, así como a su capacidad de tamponamiento [21] y [24] mencionan que en un rango apropiado, aumentar la concentración de fosfatos incrementa la capacidad de las bacterias productoras de $\mathrm{H}_{2}$ de producir $\mathrm{H}_{2}$ fermentativo.

Los iones metálicos más importantes en la producción de $\mathrm{H}_{2}$ fermentativo son el $\mathrm{Mg}^{2+}, \mathrm{Na}^{+}, \mathrm{Zn}^{2+}$ y Fe${ }^{2+}$, dado que estos elementos son necesarios para los cofactores enzimáticos, los procesos de transporte y las deshidrogenasas [25]. De estos iones el $\mathrm{Fe}^{2+}$ es el que más se ha investigado al ser un componente clave en la actividad enzimática de la hidrogenasa [26]. Los metales pesados han sido reportados como tóxicos por [22] para la producción de $\mathrm{H}_{2}$ fermentativo de acuerdo con el siguiente orden de toxicidad: $\mathrm{Cu}>\mathrm{Ni}-\mathrm{Zn}>\mathrm{Cr}>\mathrm{Cd}>\mathrm{Pb}$.

A continuación se presenta un resumen de trabajos publicados relacionados con la producción de biohidrógeno que abarcan un periodo de tiempo de
1993-2011, las diferentes condiciones con las cuales se realizaron los experimentos de producción de $\mathrm{H}_{2}$ fermentativo y los principales resultados obtenidos por los autores. Esta información se resume en forma cronológica en la Tabla 1.

Una revisión de las investigaciones referenciadas en la Tabla 1 evidencia que la mayoría de estudios se han realizado en reactores tipo batch y son pocos los experimentos efectuados en régimen continuo, esto se debe probablemente a la simple operación y control de los primeros. Los volúmenes de los reactores en batch y la cantidad de botellas utilizadas fueron muy diferentes empleando botellas de vidrio de capacidad de 70 hasta $4.000 \mathrm{ml}$ y desde 1 hasta 12 botellas, lo que se debe a la cantidad de inóculo y sustrato empleados así como a las diferentes réplicas que hace cada autor para justificar la validez de sus resultados.

En la mayoría de experimentos se emplearon como inóculo lodos anaerobios provenientes de PTAR seguido de lodos provenientes de reactores CSRT, RALFH y UASB; estos inóculos fueron pretratados principalmente mediante choque térmico y se utilizaron cultivos mixtos de bacterias. Los estudios que emplearon cultivos puros de bacterias

Tabla 1. Literatura relacionada con producción de biohidrógeno.

\begin{tabular}{|c|c|c|}
\hline Ref. & Proyecto experimental & Principales resultados \\
\hline [27] & $\begin{array}{l}\text { Régimen continuo. Inóculo proveniente } \\
\text { de PTAR. Glucosa } 11.700 \mathrm{~g} \text { como sustra- } \\
\text { to. Nutrientes } 100 \mathrm{~g} \text { extracto de levadura, } \\
5223 \mathrm{NaHCo}_{3}, 38,2 \mathrm{NH}_{4} \mathrm{Cl}, 17,3 \mathrm{Na}_{2} \mathrm{HPO}_{4} \text {, } \\
2,6 \mathrm{KH}_{2} \mathrm{PO}_{4}, 16 \mathrm{MgCl}_{2} \cdot 6 \mathrm{H}_{2} \mathrm{O}, 2,6 \mathrm{MnSO}_{4} \text {. } \\
\mathrm{H}_{2} \mathrm{O}, 0,8 \mathrm{CuSO}_{4} \cdot 5 \mathrm{H}_{2} \mathrm{O}, 0,015 \mathrm{CaCl}_{2} \cdot 2 \mathrm{H}_{2} \mathrm{O}, 4 \\
\mathrm{FeSO}_{4} \cdot 7 \mathrm{H}_{2} \mathrm{O} \text {. Temperatura } 36{ }^{\circ} \mathrm{C} \text {, volumen re- } \\
\text { actor } 1,01, \mathrm{TRS} 2,4,6,8 \text { y } 10 \mathrm{~h} \text {. }\end{array}$ & $\begin{array}{l}\text { El valor del } \mathrm{pH} \text { en el efluente varió desde } \\
5,7 \text { a } 6,3 \text {. La cantidad de bacterias anae- } \\
\text { robias en general aumentó (formadoras } \\
\text { de ácidos y las del género Clostridium), } \\
\text { las reductoras de sulfatos disminuyeron. } \\
\text { Cuando se incrementó de } 2 \text { a } 10 \text { h el TRS } \\
\text { el contenido de } \mathrm{H}_{2} \text { disminuyó de } 12 \text { a } 9 \% \text {. }\end{array}$ \\
\hline [28] & $\begin{array}{l}\text { Régimen batch. Se emplearon dos clases de inó- } \\
\text { culo, la primera de lodo de digestión anaerobia, } \\
\text { el otro de un lodo de compost. Se empleó ce- } \\
\text { lulosa en polvo } 10 \mathrm{~g} / 1 \text { como sustrato. Nutrien- } \\
\text { tes }(\mathrm{g} / \mathrm{l}): \mathrm{KH}_{2} \mathrm{PO}_{4}, 1,5 ; \mathrm{Na}_{2} \mathrm{HPO}_{4} \cdot 12 \mathrm{H}_{2} \mathrm{O}, 4,2 ; \\
\mathrm{NH}_{4} \mathrm{Cl}, 0,5 ; \mathrm{MgCl}_{2} \cdot 6 \mathrm{H}_{2} \mathrm{O}, 0,18 ; \text { extracto de al- } \\
\text { midón, } 2,0 . \mathrm{Se} \text { inocularon } 15 \mathrm{~g} \text { de la microflora } \\
\text { en } 31 \text { del medio de cultivo a } 200 \mathrm{rpm} \text { y } 60^{\circ} \mathrm{C} \text {. }\end{array}$ & $\begin{array}{l}\text { Se obtuvo después de } 120 \mathrm{~h} \text { de cultivo } \\
1.375 \mathrm{ml} / \text { cultivo de gas para los lodos de } \\
\text { digestión anaerobia con }\left(33 \% \mathrm{H}_{2}, 50 \%\right. \\
\left.\mathrm{CO}_{2} \text { y } 17 \% \mathrm{CH}_{4}\right) \text { y } 3325 \text { para el lodo de } \\
\text { compost con }\left(58 \% \mathrm{H}_{2}, 42 \% \mathrm{CO}_{2} \text { y N.D. }\right. \\
\left.\mathrm{CH}_{4}\right) \text {. Los lodos de digestión produjeron } \\
\mathrm{AGV}(\mathrm{mg} / \mathrm{l}): 1.154 \text { acetato, } 630 \text { butirato, y } \\
\text { compuestos de lodos activados } 1.724 \text { ace- } \\
\text { tato, } 1.281 \text { butirato. }\end{array}$ \\
\hline
\end{tabular}




\begin{tabular}{|c|c|c|}
\hline Ref. & Proyecto experimental & Principales resultados \\
\hline [29] & $\begin{array}{l}\text { Régimen batch. Se emplearon como inóculo } \\
\text { lodos anaerobios activados de una empresa de } \\
\text { azúcares. Agitado a } 200 \mathrm{rpm} \text { a } 60^{\circ}, \mathrm{pH} 6,8 \text {. El } \\
\text { volumen de gas se midió por el método de des- } \\
\text { plazamiento de agua. }\end{array}$ & $\begin{array}{l}\text { La máxima producción de } \mathrm{H}_{2} \text { se obtuvo a } \\
\text { un corto TRH ( } 14 \mathrm{mmol} / \mathrm{g} \text { carbohidratos a } \\
\text { TRH de } 0,5 \mathrm{~d}) \text {, la producción de AGV in- } \\
\text { crementó con el TRH. La fermentación ho- } \\
\text { moacetogénica en la cual no hay produc- } \\
\text { ción de } \mathrm{H}_{2} \text { podría ser el proceso dominante } \\
\text { a lo largo del TRH. }\end{array}$ \\
\hline [30] & $\begin{array}{l}\text { Régimen continuo (Digestor anaerobio de lecho } \\
\text { fluidizado de alta tasa). Residuos de panadería } \\
\text { (con DQO aprox. de } 12,000 \mathrm{mg} \mathrm{O}_{2} / \mathrm{l} \text { ). Operado } \\
\text { a } 37^{\circ} \mathrm{C} \text {, consistente en dos reactores conectados } \\
\text { en paralelo (volumen total líquido } 11 \text { ). La tasa } \\
\text { de biogás se midió con un medidor de gas en } \\
\text { línea con adquisición de datos cada } 6 \text { minutos. }\end{array}$ & $\begin{array}{l}\text { Al aumentar la tasa volumétrica de sustrato } \\
\text { (kg DQO/m³/día) se generaron picos en la } \\
\text { presión parcial de } \mathrm{H}_{2} \text {. No se encontró una } \\
\text { clara relación entre los niveles de digestión } \\
\text { del ácido propiónico y el biogás de hidró- } \\
\text { geno. Se presentaron variaciones conside- } \\
\text { rables en la presión del } \mathrm{H}_{2} \text { dependiendo del } \\
\text { grado de acidificación del sustrato. }\end{array}$ \\
\hline [16] & $\begin{array}{l}\text { Régimen batch. Se emplearon residuos sólidos } \\
\text { municipales mezclados con lodos y agua de } \\
\text { PTAR y dos clases de bacterias, la primera neta- } \\
\text { mente productora de } \mathrm{H}_{2} \text { y la otra de un lodo de } \\
\text { digestión anaerobia pretratado por } 15 \text { min con } \\
\text { calor. Se empleó (g/l): } \\
200 \mathrm{NH}_{4} \mathrm{HCO}_{3}, 100 \mathrm{KH}_{2} \mathrm{PO}_{4}, 10 \mathrm{MgSO}_{4} \cdot 7 \mathrm{H}_{2} \text {, } \\
1,0 \mathrm{NaCl}_{1} 1,0 \mathrm{Na}_{2} \mathrm{MoO}_{4} \cdot 2 \mathrm{H}_{2} \mathrm{O}, 10 \mathrm{CaCl}_{2} \cdot 2 \mathrm{H}_{2} \mathrm{O} \text {, } \\
1,5 \mathrm{MnSO}_{4} \cdot 7 \mathrm{H}_{2} \mathrm{O} \text { y } 0,278 \mathrm{FeCl}_{2} . \mathrm{Se}_{\text {realizó a }} \\
37^{\circ} \mathrm{C} \text {, agitación } 1,5 \mathrm{rpm} \text {. }\end{array}$ & $\begin{array}{l}\text { El porcentaje de hidrógeno en el biogás fue } \\
\text { mayor a } 60 \% \text { y nunca se obtuvo metano de } \\
\text { forma significativa. Con una alta relación } \\
\text { de alimento/microorganismo (A/M), el } \\
\text { lodo de digestión pretratado tuvo una alta } \\
\text { productividad de } \mathrm{H}_{2} \text {. Los resultados expe- } \\
\text { rimentales mostraron que se presenta un } \\
\text { cambio en la producción de solventes a un } \\
\text { pH de } 5,6 \text {. }\end{array}$ \\
\hline [31] & $\begin{array}{l}\text { Régimen continuo, reactor CSRT. El inóculo se } \\
\text { obtuvo de frijol soya. La operación del reactor } \\
\text { CSTR fue } 8,5 \mathrm{~h} \text { TRH, } 100 \mathrm{rpm}, 35^{\circ} \mathrm{C}, \mathrm{pH} 6,0 \text {. } \\
\text { Se empleó } \mathrm{N}_{2} \text { como gas de burbujeo a una tasa } \\
\text { de } 110 \mathrm{ml} / \mathrm{min} \text {. Después de } 50 \text { días de opera- } \\
\text { ción, el } \mathrm{N}_{2} \text { se burbujeó por } 49 \mathrm{~h} \text {, seguido por un } \\
\text { retorno a las condiciones normales por } 5 \text { días. } \\
\text { El segundo periodo de burbujeo duró } 4,5 \text { días. }\end{array}$ & $\begin{array}{l}\text { Se obtuvo una concentración de bioma- } \\
\text { sa floculante de } 1,5 \mathrm{~g} / \mathrm{l} \text { (peso seco) en el } \\
\text { CSTR sin burbujeo y una biomasa no flo- } \\
\text { culante de una baja concentración durante } \\
\text { el burbujeo. Se obtuvo una producción de } \\
\mathrm{H}_{2} \text { de } 0,85 \text { y } 1,43 \mathrm{~mol} / \mathrm{mol} \text { glucosa bajo } \\
\text { condiciones de no burbujeo y burbujeo; el } \\
\text { burbujeo con } \mathrm{N}_{2} \text { incrementó en un } 68 \% \text { el } \\
\mathrm{H}_{2} \text {. }\end{array}$ \\
\hline [32] & $\begin{array}{l}\text { Régimen continuo. Inóculo proveniente de una } \\
\text { PTAR. Sustrato sacarosa }(20.000 \mathrm{mg} / \mathrm{l}) \text { con con- } \\
\text { tenido de suplementos inorgánicos que incluyen } \\
\mathrm{NH}_{4} \mathrm{HCO}_{3}(5240 \mathrm{mg} / \mathrm{l}), \mathrm{K}_{2} \mathrm{HPO}_{4}(125 \mathrm{mg} / \mathrm{l}) \text {, } \\
\mathrm{MgCl}_{2} \cdot 6 \mathrm{H}_{2} \mathrm{O}(100 \mathrm{mg} / \mathrm{l}), \mathrm{MnSO}_{4} \cdot 6 \mathrm{H}_{2} \mathrm{O} \\
(15 \mathrm{mg} / \mathrm{l}), \mathrm{FeSO}_{4} \cdot 7 \mathrm{H}_{2} \mathrm{O}(25 \mathrm{mg} / \mathrm{l}), \mathrm{CuSO}_{4} \cdot 5 \mathrm{H}_{2} \mathrm{O} \\
(5 \mathrm{mg} / \mathrm{l}), \mathrm{CoCl}_{2} .5 \mathrm{H}_{2} \mathrm{O}(0,125 \mathrm{mg} / \mathrm{l}) \text { y } \mathrm{NaHCO}_{3} \\
(6720 \mathrm{mg} / \mathrm{l}) . \mathrm{Temp}^{\circ} 33^{\circ} \mathrm{C} \text { y pH } 6,7 .\end{array}$ & $\begin{array}{l}\text { Se observó que la TPH mejoró con un } \\
\text { cambio en la tasa de dilución de } 0,02 \text { a } \\
0,075 \mathrm{~h}^{-1} \text {. El ácido butírico fue el meta- } \\
\text { bolito predominante durante la operación. } \\
\text { La relación óptima de ácido butírico/ácido } \\
\text { acético empleando glucosa para Clostri- } \\
\text { dium butyricum y Bacillus methylotrophi- } \\
\text { cum fue } 2 \text { y } 0,75 \text {, respectivamente. }\end{array}$ \\
\hline
\end{tabular}




\begin{tabular}{|c|c|c|}
\hline Ref. & Proyecto experimental & Principales resultados \\
\hline [15] & $\begin{array}{l}\text { Régimen batch. Se emplearon cuatro especies } \\
\text { diferentes de bacterias metanogénicas: Metha- } \\
\text { nothermobacter marburgensis con un preculti- } \\
\text { vo a } 65^{\circ} \mathrm{C} \text { y pH } 7,5 \text { en un medio de sales mi- } \\
\text { nerales. Methanosarcina barkeri con una temp. } \\
37{ }^{\circ} \mathrm{C} \text { y pH } 6,7 \text { en sales minerales, estas dos } \\
\text { bacterias crecieron en un sustrato únicamente } \\
\text { con } \mathrm{H}_{2} \text { y } \mathrm{CO}_{2} \text {. Methanosaeta thermophilia cre- } \\
\text { ció a } 61{ }^{\circ} \mathrm{C} \text { y pH } 6,5 \text { en un medio con acetato. } \\
\text { Methanosaeta concilii que es obligatoriamente } \\
\text { acetoclástica creció empleando el mismo medio } \\
\text { a } 35^{\circ} \mathrm{C} \text { y pH } 7 \text {. }\end{array}$ & $\begin{array}{l}\text { Las dos especies de Methanosaeta emplean } \\
\text { rutas que difieren significativamente de las } \\
\text { rutas de } \mathrm{H}_{2} / \mathrm{CO}_{2} \text {. Los resultados indican } \\
\text { que la producción de } \mathrm{H}_{2} \text { en Methanother- } \\
\text { mobacter marburgensis y Methanosarci- } \\
\text { na barkeri es controlada biológicamente } \\
\text { y que el } \mathrm{H}_{2} \text { se produce de los metabolitos } \\
\text { elaborados durante el crecimiento de los } \\
\text { precultivos. La producción estimada de } \mathrm{H}_{2} \\
\text { para las tres especies productoras varió de } \\
0,16 \text { a } 0,25 \mu \mathrm{mol}_{2} \text {. }\end{array}$ \\
\hline [33] & $\begin{array}{l}\text { Régimen batch. El inóculo se tomó de un diges- } \\
\text { tor a escala laboratorio. Un litro del medio con- } \\
\text { tenía } \mathrm{NH}_{4} \mathrm{HCO}_{3} 2 \mathrm{~g}, \mathrm{KH}_{2} \mathrm{PO}_{4} 1 \mathrm{~g}, \mathrm{MgSO}_{4} \cdot 7 \mathrm{H}_{2} \mathrm{O} \\
100 \mathrm{mg}, \mathrm{NaCl} 10 \mathrm{mg}, \mathrm{Na}_{2} \mathrm{MoO}_{4} \cdot 2 \mathrm{H}_{2} \mathrm{O} 10 \mathrm{mg} \text {, } \\
\mathrm{CaCl}_{2} \cdot 2 \mathrm{H}_{2} \mathrm{O} 10 \mathrm{mg}, \mathrm{MnSO}_{4} \cdot 7 \mathrm{H}_{2} \mathrm{O} 15 \mathrm{mg} \text {. } \\
\mathrm{Temp} .37^{\circ} \mathrm{C}, \mathrm{pH} 6,0 . \text { A cada botella se adicio- } \\
\text { naron } 20 \mathrm{ml} \text { de inóculo, } 20 \mathrm{ml} \text { de sustrato, } 20 \mathrm{ml} \\
\text { de la solución de sacarosa }(40 \mathrm{~g} / \mathrm{l}) \text { y } 20 \mathrm{ml} \mathrm{de} \\
\text { solución de } \mathrm{FeCl} 2 \text { (varió de } 0 \text { a } 16 \mathrm{~g} \mathrm{FeCl} / \mathrm{ll}) \text {. La } \\
\text { producción de biogás se determinó empleando } \\
\text { el método Owen. }\end{array}$ & $\begin{array}{l}\text { La TPH de } \mathrm{H}_{2} \text { fue } 24 \mathrm{ml} / \mathrm{g} \mathrm{SSV} / \mathrm{h} \text { a una } \\
\text { concentración de } 4000 \mathrm{mg} \mathrm{FeCl} / \mathrm{l} \text {. La TEP } \\
\text { de butirato incrementó con el aumento en } \\
\text { la concen. de Fe de } 0-20 \mathrm{mg} \mathrm{FeCl}_{2} / \mathrm{l} \text {, y dis- } \\
\text { min con un aument. en la concentración de } \\
\mathrm{Fe} \text { de } 20-4000 \mathrm{mg} \mathrm{FeCl} / \mathrm{l} \text {. La producción } \\
\text { máxima de acetato }(389,3 \mathrm{mg} / \mathrm{g} \text { sacarosa), } \\
\text { propionato ( } 37,8 \mathrm{mg} / \mathrm{g} \text { sacarosa) y butira- } \\
\text { to ( } 196,5 \mathrm{mg} / \mathrm{g} \text { sacarosa) se obtuvo a una } \\
\text { concentración de Fe de } 3,200 \text { y } 200 \mathrm{mg} \\
\mathrm{FeCl}_{2} / 1 \text { respectivamente. }\end{array}$ \\
\hline [34] & $\begin{array}{l}\text { Régimen batch por liberación periódica (mé- } \\
\text { todo Owen) o continua (método respirométri- } \\
\mathrm{co} \text { ) de gas del headspace. Inóculo se tomaron } \\
10 \mathrm{~cm} \text { de profundidad. Cada muestra se realizó } \\
\text { choque térmico } 104{ }^{\circ} \mathrm{C} \text { por } 2 \mathrm{~h} \text {. Las muestras } \\
\text { se tamizaron en malla \#20. Sustrato glucosa, } \\
\text { sacarosa, lactato y almidón de papa, celulosa } \\
\text { y molasas. La solución de nutrientes contenía } \\
\text { (por l) } 2,0 \mathrm{~g} \mathrm{NH} \mathrm{HCO}_{3}, 1,0 \mathrm{~g} \mathrm{KH}_{2} \mathrm{PO}_{4}, 100 \mathrm{mg} \\
\mathrm{MgSO}_{4} \cdot 7 \mathrm{H}_{2} \mathrm{O}, 15 \mathrm{mg} \mathrm{MnSO}_{4} \cdot 7 \mathrm{H}_{2} \mathrm{O} \text { y } 2,78 \mathrm{mg} \\
\mathrm{FeCl}_{2} \text {. Todas las botellas se agitaron y se mantu- } \\
\text { vieron a temperatura constante } 26{ }^{\circ} \mathrm{C}\end{array}$ & $\begin{array}{l}\text { La producción de } \mathrm{H}_{2} \text { fue } 43 \% \text { mayor en las } \\
\text { botellas con los respirómetros que en las } \\
\text { botellas con el método Owen. El máximo } \\
\text { porcentaje de } \mathrm{H}_{2}(64 \%) \text { se alcanzó a las } \\
44 \text { h y empezó a declinar a partir de este } \\
\text { tiempo. Las pruebas de fermentación con } \\
\text { dos azúcares (glucosa y sacarosa) produ- } \\
\text { jeron altas concentraciones de } \mathrm{H}_{2} 62 \% \text {. } \\
\text { La baja producción de } \mathrm{H}_{2} \text { con el método } \\
\text { Owen comparado con el respirométrico su- } \\
\text { giere que la acumulación del gas inhibe la } \\
\text { producción de } \mathrm{H}_{2} \text {. }\end{array}$ \\
\hline [35] & $\begin{array}{l}\text { Régimen continuo. Se obtuvo inóculo de PTAR, } \\
\text { se acidificó a pH 3-4 por } 24 \text { h y después se cam- } \\
\text { bió a pH 7. El medio contenía } 20 \text { g/l sacarosa } \\
\text { y }(\mathrm{g} / \mathrm{l}): \mathrm{NH}_{4} \mathrm{HCO}_{3} 5.24 ; \mathrm{NaHCO}_{3} 6,72 ; \mathrm{K}_{2} \mathrm{H}- \\
\mathrm{PO}_{4} 0,125 ; \mathrm{MgCl}_{2} \cdot 6 \mathrm{H}_{2} \mathrm{O} 0,100 ; \mathrm{MnSO}_{4} \cdot 6 \mathrm{H}_{2} \mathrm{O} \\
0,015 ; \mathrm{FeSO}_{4} \cdot 7 \mathrm{H}_{2} \mathrm{O} 0,025 ; \mathrm{CuSO}_{4} \cdot 5 \mathrm{H}_{2} \mathrm{O} 0,005 \\
\text { y } \mathrm{CoCl}_{2} .5 \mathrm{H}_{2} \mathrm{O} 1,25 \times 10^{-4} . \mathrm{El} \text { reactor fue opera- } \\
\text { do a TRH de } 0,5-5 \mathrm{~h}, \mathrm{Temp} .35^{\circ} \mathrm{C} \text { y un pH } 6,7 \text {. } \\
\text { Las columnas tenían como material de soporte } \\
\text { esponja estropajo EE, arcilla expansiva AE y } \\
\text { carbón activado CA. }\end{array}$ & $\begin{array}{l}\text { Las columnas con medio de CA, AE, EE } \\
\text { acumularon } 5,53,1,85 \text { y } 0,94 \mathrm{~g} \mathrm{SSV} / \mathrm{l} \text { de } \\
\text { biomasa, respectivamente. La producción } \\
\text { de } \mathrm{H}_{2} \text { al final de la operación fue } 1010 \text { y } \\
980 \mathrm{ml} \text { para el reactor de CA y AE para } \\
\text { el reactor EE solo } 190 \mathrm{ml} \text {. En este estu- } \\
\text { dio la mejor tasa de producción de } \mathrm{H}_{2} \text { fue } \\
1,32 \mathrm{l} / \mathrm{h} / \mathrm{l} \text { para el reactor CA y THR=1 h y } \\
0,42 \mathrm{l} / \mathrm{h} / 1 \text { para AE a un TRH=2h. El mejor } \\
\text { reactor para producción de } \mathrm{H}_{2} \text { fue el CA. }\end{array}$ \\
\hline
\end{tabular}




\begin{tabular}{|c|c|c|}
\hline Ref. & Proyecto experimental & Principales resultados \\
\hline [36] & $\begin{array}{l}\text { Régimen continuo, reactor CSTR. Inóculo se } \\
\text { obtuvo de una PTAR. El medio contenía saca- } \\
\text { rosa } 20.000 \mathrm{mg} / \mathrm{l} \text {, con nutrientes }(\mathrm{mg} / \mathrm{l}): 5240 \\
\mathrm{NH}_{4} \mathrm{HCO}_{3}, 125 \mathrm{~K}_{2} \mathrm{HPO}_{4}, 100 \mathrm{MgCl}_{2} \cdot 6 \mathrm{H}_{2} \mathrm{O}, 15 \\
\mathrm{MnSO}_{4} \cdot 6 \mathrm{H}_{2} \mathrm{O}, 25 \mathrm{FeSO}_{4} \cdot 7 \mathrm{H}_{2} \mathrm{O}, 5 \mathrm{CuSO}_{4} \cdot 5 \mathrm{H}_{2} \mathrm{O} \text {, } \\
0,125 \mathrm{CoCl}_{2} .5 \mathrm{H}_{2} \mathrm{O}, 6720 \mathrm{NaHCO}_{3} . \mathrm{El}_{\text {sustrato }} \\
\text { se alimentó en continuo a TRH } 13,3 \mathrm{~h} \text {, la temp. } \\
\text { de operación fue } 35{ }^{\circ} \mathrm{C} \text {. }\end{array}$ & $\begin{array}{l}\text { La producción de } \mathrm{H}_{2} \text { aumentó cuando se } \\
\text { disminuyó el TRH hasta } 2 \mathrm{~h} \text {, después de } \\
\text { este valor la producción de } \mathrm{H}_{2} \text { disminuyó. } \\
\text { Bajo condiciones estables se obtuvo una } \\
\text { producción de } \mathrm{H}_{2} \text { de } 4,52 \mathrm{ml} \mathrm{H}_{2} / \text { mol saca- } \\
\text { rosa y una tasa de producción específica de } \\
841 \mathrm{mmol} \mathrm{H}_{2} / \mathrm{g} \mathrm{SSV} \text { día. }\end{array}$ \\
\hline [37] & $\begin{array}{l}\text { Régimen batch. Se empleó lodo de un diges- } \\
\text { tor anaerobio. Se utilizó glucosa ( } 3 \mathrm{~g} / \mathrm{l} \text { ) en una } \\
\text { solución que contenía (por litro): } 0,5 \mathrm{~g} \mathrm{NH} \text { - } \\
{ }_{4} \mathrm{Cl}, 0,25 \mathrm{~g} \mathrm{KH}_{2} \mathrm{PO}_{4}, 0,25 \mathrm{~g} \mathrm{~K}_{2} \mathrm{HPO}_{4}, 300 \mathrm{mg} \\
\mathrm{MgCl}_{2} \cdot 6 \mathrm{H}_{2} \mathrm{O}, 25 \mathrm{mg} \mathrm{FeCl}{ }_{3}, 16 \mathrm{mg} \mathrm{NiSO} \text {, } \\
25 \mathrm{mg} \mathrm{CaCl}_{2}, 11,5 \mathrm{mg} \mathrm{ZnCl}, 10,5 \mathrm{CoCl}_{2} 6 \mathrm{H}_{2} \mathrm{O} \text {, } \\
5 \mathrm{mg} \mathrm{CuCl}_{2} \cdot 2 \mathrm{H}_{2} \mathrm{O} \text { y } 15 \mathrm{mg} \mathrm{MnCl}_{2} \cdot 4 \mathrm{H}_{2} \mathrm{O} \text {. }\end{array}$ & $\begin{array}{l}\text { Se obtuvo una tasa máxima de biogás de } \\
145 \text { ml cuando el inóculo fue pretratado } \\
\text { con calor y se operó a un pH } 6,2 \text {. Los AGV } \\
\text { predominantes fueron acetato, propianato } \\
\text { y butirato. Bajar el pH } 7,5 \text { hasta } 6,2 \text { para } \\
\text { las muestras no tratadas y tratadas reduce } \\
\text { la producción de metano. }\end{array}$ \\
\hline [38] & $\begin{array}{l}\text { Régimen batch. Inóculo obtenido de compost } \\
\text { pretratado a } 105{ }^{\circ} \mathrm{C} \text { por } 2 \mathrm{~h} \text {. Se adicionó } 1,5 \mathrm{~g} \\
\text { de sacarosa o } 10 \mathrm{ml} \text { de solución de almidón } \\
(150 \mathrm{~g} / \mathrm{l}) \text { y } 0,5 \mathrm{ml} \text { de solución de nutrientes que } \\
\text { contenían }(\mathrm{g} / \mathrm{l}): 200 \mathrm{NH}_{4} \mathrm{HCO}_{3}, 100 \mathrm{KH}_{2} \mathrm{PO}_{4} \text {, } \\
10 \mathrm{MgSO}_{4} \cdot 7 \mathrm{H}_{2} \mathrm{O}, 1 \mathrm{NaCl}, 1 \mathrm{Na}_{2} \mathrm{MoO}_{4} \cdot 2 \mathrm{H}_{2} \mathrm{O} \text {, } \\
1 \mathrm{CaCl}_{2} \cdot 2 \mathrm{H}_{2} \mathrm{O}, 1,5 \mathrm{MgSO}_{4} \cdot 7 \mathrm{H}_{2} \mathrm{O} \text { y } 0,278 \mathrm{FeCl}_{2} \text {. } \\
\text { El pH se varió de } 4,5-6,5 \text { en incremento de } 0,5 \text {, } \\
\text { agitación } 180 \mathrm{rpm} \text { a } 37^{\circ} \mathrm{C} \text {. }\end{array}$ & $\begin{array}{l}\text { Se encontró que el } \mathrm{pH} \text { inicial tiene un efec- } \\
\text { to en la producción de } \mathrm{H}_{2} \text {. A un pH inicial } \\
\text { bajo existe mayor potencial de producción } \\
\text { de } \mathrm{H}_{2} \text {, pero se presenta una baja tasa. La } \\
\text { máxima producción de } \mathrm{H}_{2} \text { fue } 214 \mathrm{ml} \mathrm{H}_{2} / \mathrm{g} \\
\text { DQO y } 125 \mathrm{ml} \mathrm{H}_{2} / \mathrm{g} \text { DQO a un } \mathrm{pH} \text { de } 4,5 \\
\text { para la sacarosa y el almidón respectiva- } \\
\text { mente. Se encontró que el rango de pH óp- } \\
\text { timo estuvo entre 5,5-5,7. }\end{array}$ \\
\hline [39] & $\begin{array}{l}\text { Régimen batch. Cultivo puro con bacterias } \\
\text { Clostridium saccharoperbutylacetonicum. Se } \\
\text { empleó como inóculo suero de queso, el cual } \\
\text { se diluyó a } 87,5 \% \text { y se adicionaron } 0.3 \mathrm{~g} / 1 \text { de } \\
\mathrm{MgSO}_{4} .7 \mathrm{H}_{2} \mathrm{O} \text { y } 50 \mathrm{mg} / 1 \text { de } \mathrm{FeSO}_{4} .7 \mathrm{H}_{2} \mathrm{O} \text { como } \\
\text { nutrientes. La fermentación se realizó en bote- } \\
\text { llas de } 200 \text { a } 250 \mathrm{ml} \text { a } 30^{\circ} \mathrm{C} \text { agitadas a } 50 \mathrm{rpm} \text {, } \\
\text { con variación de pH de } 5,0-10 \text {. }\end{array}$ & $\begin{array}{l}\text { Se encontró que el } \mathrm{pH} \text { inicial afecta la } \\
\text { producción de } \mathrm{H}_{2} \text {, la fase de crecimiento } \\
\text { microbiano y los tiempos de fermentación. } \\
\text { Un pH inicial levemente ácido favorece } \\
\text { la producción de } \mathrm{H}_{2} \text {. El máximo poten- } \\
\text { cial, rendimiento y tasa de producción de } \\
\mathrm{H}_{2} \text { fue de } 1432 \mathrm{ml}, 7,89 \mathrm{mmol} / \mathrm{g} \text { lactosa y } \\
47,07 \mathrm{ml} / \mathrm{h} \text { respectivamente a un pH de } 6,0 \text {. }\end{array}$ \\
\hline [40] & $\begin{array}{l}\text { Régimen batch. Inóculo de PTAR. Sustrato } \\
\text { de pasta de arroz con (mg/l): } \mathrm{NaHCO}_{3} 1250 \text {, } \\
\mathrm{NH}_{4} \mathrm{Cl} 2500, \mathrm{KH}_{2} \mathrm{PO}_{4} 250, \mathrm{~K}_{2} \mathrm{HPO}_{4} 250, \mathrm{CaCl}_{2} \\
500, \mathrm{NiSO}_{4} 32, \mathrm{MgSO}_{4} \cdot 7 \mathrm{H}_{2} \mathrm{O} 320, \mathrm{FeCl}_{3} 20, \mathrm{Na}- \\
{ }_{2} \mathrm{BO}_{4} \cdot \mathrm{H}_{2} \mathrm{O} 7,2, \mathrm{Na}_{2} \mathrm{MoO}_{4} \cdot 2 \mathrm{H}_{2} \mathrm{O} 14,4, \mathrm{ZnCl}_{2} 23 \text {, } \\
\mathrm{CoCl}_{2} \cdot 6 \mathrm{H}_{2} \mathrm{O} 21, \mathrm{CuCl}_{2} \cdot \mathrm{H}_{2} \mathrm{O} 10, \mathrm{MnCl}_{2} \cdot 4 \mathrm{H}_{2} \mathrm{O} \\
\text { 30, extracto de almidón } 50 .\end{array}$ & $\begin{array}{l}\text { La producción de } \mathrm{H}_{2} \text { a partir de pasta de } \\
\text { arroz fue óptima a pH } 4,5,37^{\circ} \mathrm{C} \text {, con con- } \\
\text { tenido de pasta de } 5,5 \mathrm{~g} \text { carbohidratos } / \mathrm{l} \text {, } \\
\text { empleando un lodo de digestión pretratado } \\
\text { a } 100^{\circ} \mathrm{C} \text { por } 30 \text { min. Se obtuvo un máximo } \\
\text { de } 346 \mathrm{ml} / \mathrm{g} \text { carbohidrato y TPHE } 2,1 \mathrm{1} / \mathrm{g} \\
\text { SSV.d después de } 36 \text { h de aclimatación. }\end{array}$ \\
\hline [41] & $\begin{array}{l}\text { Régimen batch. Compost pretratado a } 85{ }^{\circ} \mathrm{C} \text { por } \\
\text { 3h. Se emplearon granos de malta como sustrato } \\
\text { con nutrientes }(\mathrm{g} / \mathrm{l}): 80 \mathrm{NH}_{4} \mathrm{CO}_{3}, 40 \mathrm{KH}_{2} \mathrm{PO}, 4 \\
\mathrm{MgSO}_{4} .7 \mathrm{H}_{2} \mathrm{O} \text { y } 11 \mathrm{FeCl}_{2} . \mathrm{Se} \text { realizaron } 24 \text { ex- } \\
\text { perimentos donde se varió el pH de } 5,0-6,5 \mathrm{con} \\
\text { increm. } 0.5 \text { y agitación desde } 25 \text { hasta } 250 \mathrm{rpm} \text {. }\end{array}$ & $\begin{array}{l}\text { El pH fue más importante que la veloci- } \\
\text { dad de agitación en la producción de } \mathrm{H}_{2} \text {. } \\
\text { La condición óptima de } \mathrm{pH} \text { y velocidad } \\
\text { de agitación fue } 6,0 \text { y } 120 \mathrm{rpm} \text { generando } \\
161 \mathrm{ml} \mathrm{H}_{2} / \mathrm{g} \mathrm{SST} / \mathrm{d} \text { y } 13 \mathrm{ml} \mathrm{H}_{2} / \mathrm{g} \mathrm{SST} \text {. }\end{array}$ \\
\hline
\end{tabular}




\begin{tabular}{|c|c|c|}
\hline Ref. & Proyecto experimental & Principales resultados \\
\hline [42] & $\begin{array}{l}\text { Régimen continuo, reactor RAHLF. Las bacte- } \\
\text { rias se obtuvieron por fermentación natural de } \\
\text { agua residual sintética, la cual se recirculó en el } \\
\text { RAHLF. El sustrato contenía glucosa y minera- } \\
\text { les como nutrientes. El reactor se operó por } 366 \\
\text { días en } 7 \text { fases experimentales. Las } 2 \text { iniciales } \\
\text { tenían un TRH de } 2,0 \mathrm{~h} \text {, la 3ra varió de } 2-0,5 \text { h y } \\
\text { las otras tenían un TRH constante de } 0,5 \text { h. }\end{array}$ & $\begin{array}{l}\text { La producción de } \mathrm{H}_{2} \text { fue de } 2,48,2,15 \text { y } \\
1,81 \text { mol } \mathrm{H}_{2} / \text { mol de glucosa para concen- } \\
\text { traciones de } 0,1000 \text { y } 2000 \mathrm{mg} / 1 \text { de } \mathrm{NaH}- \\
\mathrm{CO}_{3} \text {. El aumento del pH por el } \mathrm{NaHCO}_{3} \\
\text { afectó la producción de ácidos orgánicos } \\
\text { e } \mathrm{H}_{2} \text { a excepción del ácido propiónico, el } \\
\text { cual aumentó cuando incrementó la alca- } \\
\text { linidad. }\end{array}$ \\
\hline [43] & $\begin{array}{l}\text { Régimen batch. El inóculo se tomó de un reac- } \\
\text { tor de lecho empacado empleado para producir } \\
\mathrm{H}_{2} \text { de sustrato sintético basado en sacarosa. Se } \\
\text { emplearon tres clases de efluentes: agua resi- } \\
\text { dual doméstica, vinaza y glicerina y un control } \\
\text { con sacarosa como sustrato, se adicionaron nu- } \\
\text { trientes. Temp. } 25^{\circ} \mathrm{C} \text { sin agitación, pH 5,5. }\end{array}$ & $\begin{array}{l}\text { La máxima producción } \mathrm{H}_{2} \text { fue obtenida } \\
\text { de la vinaza equivalente a } 25 \mathrm{mmol} \mathrm{H}_{2} / \mathrm{g} \\
\text { DQO o } 17 \mathrm{mmol} \mathrm{H}_{2} / \mathrm{g} \mathrm{SSV} \text {. La menor } \\
\text { producción se obtuvo con glicerina con } 6 \\
\text { mmolH } \mathrm{H}_{2} / \mathrm{g} \text { DQO. De acuerdo con evalua- } \\
\text { ción microbiológica se encontraron Kleb- } \\
\text { siella sp consumidora de } \mathrm{O}_{2} \text { y Bacteroides } \\
\text { sp productora de } \mathrm{H}_{2} \text {. }\end{array}$ \\
\hline [44] & $\begin{array}{l}\text { Régimen batch. El inóculo se obtuvo de un } \\
\text { reactor UASB de tratamiento de aguas de un } \\
\text { frigorífico; posteriormente se realizó un pre- } \\
\text { tratamiento a } 90{ }^{\circ} \mathrm{C} \text { por } 15 \mathrm{~min} \text {. Se emplearon } \\
\text { cuatro sustratos que contenían xilosa en tripli- } \\
\text { cado con concentraciones de } 630,1341,1848 \text { y } \\
3588 \mathrm{mg} / 1 \text { respectivamente, urea, peptona y so- } \\
\text { lución de vitamina y suplemento de nutrientes. } \\
\text { Temp. } 37^{\circ} \mathrm{C} \text {, sin agitación pH 5,5. }\end{array}$ & $\begin{array}{l}\text { La adición de peptona favoreció el creci- } \\
\text { miento de bacterias productoras de } \mathrm{H}_{2} \text {. El } \\
\text { análisis genético mostró que el } 57 \% \text { de los } \\
\text { microorganismos pertenecían al género } \\
\text { Clostridium, } 30 \% \text { al Burkholderia, } 8 \% \text { a } \\
\text { Klebsiella y } 5 \% \text { bacterias no cultivadas. La } \\
\text { concentración de xilosa de } 3588 \mathrm{mg} / 1 \text { ge- } \\
\text { neró los mejores resultados en producción } \\
\text { de } \mathrm{H}_{2} \text { con } 12882,9 \mu \text { mol } \mathrm{H}_{2} / 1 \text { y rendimien- } \\
\text { to } 0,8 \mathrm{~mol} \mathrm{H}_{2} / \mathrm{mol} \text { de xilosa. }\end{array}$ \\
\hline [45] & $\begin{array}{l}\text { Régimen batch. Inóculo estiércol de elefan- } \\
\text { te precal. a } 100{ }^{\circ} \mathrm{C} \text {. Sustrato } 10 \mathrm{~g} / \mathrm{L} \text { de gluco- } \\
\text { sa y nutrientes por } \mathrm{L}: 200 \mathrm{~g} \mathrm{NH}_{4} \mathrm{HCO}_{3}, 100 \mathrm{~g} \\
\mathrm{KH}_{2} \mathrm{PO}_{4}, 10 \mathrm{~g} \mathrm{MgSO}_{4} \cdot 7 \mathrm{H}_{2} \mathrm{O}, 1 \mathrm{~g} \mathrm{NaCl}, 1 \mathrm{~g} \\
\mathrm{Na}_{2} \mathrm{MoO}_{4} \cdot 2 \mathrm{H}_{2} \mathrm{O}, 1 \mathrm{~g} \mathrm{CaCl}_{2} \cdot 2 \mathrm{H}_{2} \mathrm{O} \text { y } 0,278 \mathrm{~g} \\
\mathrm{FeCl}_{2} . \text { Se desarrolló en botellas de } 70 \mathrm{ml} \text {, con } \\
12 \mathrm{ml} \text { de inóculo, } 28 \mathrm{ml} \text { de bagazo de caña de } \\
\text { azúcar y } 20 \mu \mathrm{l} \text { de solución de nutrientes. Temp. } \\
37^{\circ} \mathrm{C} \text {. }\end{array}$ & $\begin{array}{l}\text { La condición óptima para pretratamiento } \\
\text { de bagazo de caña fue una hidrólisis ácida } \\
\text { con } \mathrm{H}_{2} \mathrm{SO}_{4} \text { a una concentración de } 1,0 \% \\
\text { (v/v). La máxima producción de } \mathrm{H}_{2} \text { en tér- } \\
\text { minos de rendimiento y TPH fue } 0,84 \mathrm{~mol} \\
\mathrm{H}_{2} / \text { mol de azúcar total y } 109,55 \mathrm{ml} \mathrm{H}_{2} / 1 \\
\text { día, respectivamente, obtenido con un pH } \\
\text { inicial de } 6,5 \text { y concentración de sustrato } \\
\text { de } 10 \mathrm{~g} / \mathrm{l} \text {. }\end{array}$ \\
\hline
\end{tabular}

se realizaron en régimen batch y empleando glucosa como sustrato. En algunos estudios se emplearon compuestos orgánicos especiales como estiércol de elefante, compost y residuos industriales.

Los estudios han utilizado principalmente glucosa, sacarosa y almidón respectivamente como sustratos, en concentraciones que variaban desde 300 hasta $11.700 \mathrm{mg} / \mathrm{l}$ para la glucosa, en los estudios que se empleó sacarosa las concentraciones fueron de $20.000 \mathrm{mg} / \mathrm{l}$ y para el almidón de $200 \mathrm{mg} / \mathrm{l}$. Otros sustratos empleados fueron celulosa en polvo, peptonas, xilosa y lactato, los cuales se utilizaron a diferentes concentraciones.

Los nutrientes empleados contenían una fuente de fosfatos, los cuales se obtenían de la adición de $\mathrm{KH}_{2} \mathrm{PO}_{4}$ en concentraciones que variaban desde $125 \mathrm{mg} / \mathrm{l}$ hasta $250 \mathrm{~g} / \mathrm{l}$, una fuente de nitrógeno obtenida de la adición de $\mathrm{NH}_{4} \mathrm{Cl}$ principalmente en concentraciones desde $17,3 \mathrm{mg} / \mathrm{l}$ hasta $12,5 \mathrm{~g} / \mathrm{l}$ o $\mathrm{NH}_{4} \mathrm{HCO}_{3}$ en concentraciones de $2 \mathrm{~g} / \mathrm{l}$ hasta $200 \mathrm{~g} / \mathrm{l}$ 
y iones metálicos $\mathrm{Mg}^{2+}, \mathrm{Na}^{+}, \mathrm{Zn}^{2+}$ y $\mathrm{Fe}^{2+}$ obtenidos de diferentes sales con distintas concentraciones.

Los autores reportan diferentes condiciones de operación de temperatura, $\mathrm{pH}$ y TRH. La mayoría de estudios se realizaron en un rango de temperatura mesofílico variando desde 26 hasta $37^{\circ} \mathrm{C}$ y algunas en rango termofílico con variaciones entre 55 hasta $65^{\circ} \mathrm{C}$, ninguno en rango hipertermofílico $>80^{\circ} \mathrm{C}$. El $\mathrm{pH}$ inicial utilizado por los autores se desarrolló en un rango entre 4,0-7,5, empleándose en la mayoría de estudios pH ácidos leves entre 6,0-7,0. Los TRH utilizados variaron entre $0,5-13,3 \mathrm{~h}$, empleándose principalmente TRH en un rango entre 6,0-8,0 h.

Los reactores han generado producciones de $\mathrm{H}_{2}$ muy variables, las cuales no son comparativas en la mayoría de los casos puesto que la cantidad de $\mathrm{H}_{2}$ se ha cuantificado en términos de rendimiento, TPH, TPEH y en términos de biomasa, las cuales no son unidades homólogas entre sí. Teniendo en cuenta lo anterior, las producciones de $\mathrm{H}_{2}$ en los estudios variaron en términos de rendimiento entre 0,85 hasta $2,48 \mathrm{~mol} \mathrm{H}_{2} / \mathrm{mol}$ de glucosa, TPH entre 4,56 $\mathrm{ml} \mathrm{H}_{2} / \mathrm{l}$.h hasta $1,321 \mathrm{H}_{2} / \mathrm{l}$.h, TPEH entre 3,73 hasta $17 \mathrm{mmol} \mathrm{H}_{2} / \mathrm{g}$ SSV y en términos de biomasa $15,20-24 \mathrm{ml} / \mathrm{g} \mathrm{SSV} / \mathrm{h}$.

En aquellos estudios donde se realizó un análisis de la producción de $\mathrm{AGV}$ se generaron ácidos grasos de acuerdo con el siguiente orden: acético, butírico y propiónico, lo cual indica que se favoreció la ruta de producción donde se genera como subproducto acetato principalmente, siendo esta la ruta que produce más $\mathrm{H}_{2}$ fermentativo. La producción de los otros ácidos no es tan favorable para la generación de $\mathrm{H}_{2}$, por tanto su presencia es un indicativo de que el proceso no ha sido completamente controlado.

Como se evidencia en los estudios no se ha obtenido la máxima producción teórica de $\mathrm{H}_{2}$ fermentativo, lo cual demuestra que aún es posible mejorar las condiciones que afectan la producción de biohidrógeno.

\section{RETOS Y PERSPECTIVAS FUTURAS}

La fermentación oscura, las rutas de producción de $\mathrm{H}_{2}$ y los factores que afectan la producción de $\mathrm{H}_{2}$ anteriormente mencionados han sido estudiados por numerosas investigaciones en todo el mundo en los últimos años. Los estudios realizados han buscado obtener la mayor producción factible de $\mathrm{H}_{2}$ fermentativo, estos a su vez se han basado en la selección de algunos factores, los cuales son variados de manera controlada para evaluar los efectos en la producción de $\mathrm{H}_{2}$. Dado que el proceso de producción de $\mathrm{H}_{2}$ fermentativo está influenciado por múltiples factores, es adecuado que se emplee un estudio experimental para evaluar el efecto de los diferentes factores involucrados en el proceso para comprender mejor y optimizar el desempeño de la producción [2].

De acuerdo con lo anterior y la revisión de la literatura realizada los parámetros no han sido todos optimizados para la producción de $\mathrm{H}_{2}$, más aún si se tiene en cuenta que el $\mathrm{H}_{2}$ se puede obtener de diversas maneras en diferentes cantidades; una evidencia sustancial que muestra que no se han obtenido valores óptimos es que en la producción de $\mathrm{H}_{2}$ por procesos fermentativos no se ha conseguido llegar al máximo teórico de $4 \mathrm{~mol} / \mathrm{mol}$ de glucosa. Se espera en el futuro obtener una mayor cantidad de $\mathrm{H}_{2}$ a partir de la optimización de los factores que influyen en la producción. Adicionalmente, al revisar casi 600 publicaciones en revistas especializadas en recursos energéticos se observa un interés de la comunidad científica en la última década en el tema de producción de biohidrógeno como se observa en la Figura 4, y se espera que esta tendencia se mantenga dadas las desventajas de los combustibles fósiles. Es interesante observar que el mayor interés en la investigación de producción de biohidrógeno se ha enfocado en China y Taiwán; en estos países se ha realizado más del 30 por ciento de las publicaciones en este tema como se muestra en la Figura 5, asimismo es importante resaltar la escasa investigación desarrollada en los países de América Latina donde en su mayoría se ha concentrado en Brasil. Se espera para el futuro un mayor interés en América Latina en el tema de producción de biohidrógeno dada la dependencia actual de combustibles fósiles, el costo de ellos y la poca oferta de fuentes energéticas alternativas, lo cual podría ser un factor determinante en el crecimiento económico de la región. 


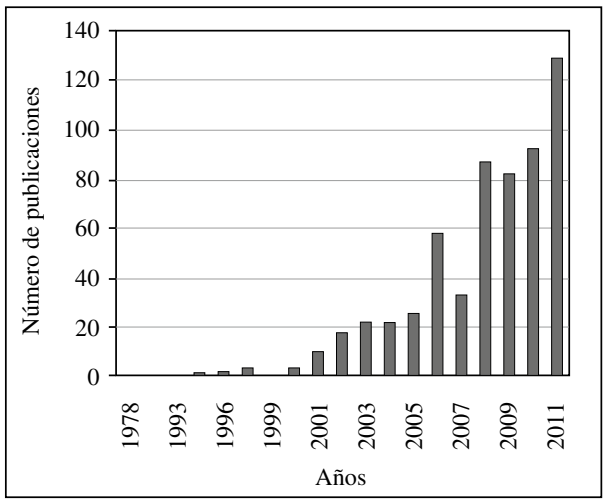

Figura 4. Publicaciones en biohidrógeno entre el periodo 1978-2011.

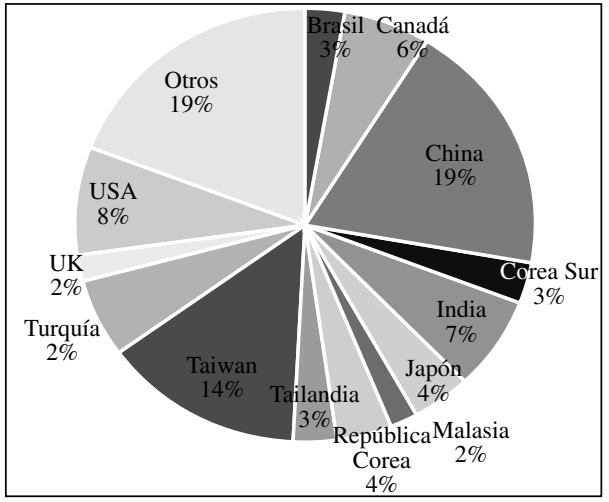

Figura 5. Publicaciones en biohidrógeno por países.

\section{CONCLUSIONES}

A pesar de que la producción de biohidrógeno por fermentación oscura de residuos ha sido ampliamente estudiada, aún quedan muchos aspectos por mejorar. En este artículo se ha discutido todo el proceso y cuáles son los factores que afectan la producción. En este sentido se puede concluir lo siguiente: primero, como no se ha obtenido la máxima producción teórica de hidrógeno se deben realizar más estudios que incluyan optimización de los factores, escalamiento de los reactores preferiblemente con producción continua, incrementar los estudios en biología molecular y caracterización de especies productoras.

Finalmente, es importante mencionar que en América Latina debe promoverse el desarrollo de más investigación para así generar una mayor diversidad de fuentes energéticas e independencia de los combustibles fósiles.

\section{AGRADECIMIENTOS}

Los autores desean expresar sus agradecimientos por el apoyo financiero al Departamento Administrativo de Ciencia, Tecnología e Investigación - COLCIENCIAS y a la Universidad Militar Nueva Granada - UMNG a través del Programa Jóvenes Investigadores e Innovadores "Virginia Gutiérrez de Pineda" año 2011.

\section{REFERENCIAS}

[1] H. Argun and F. Kargi. "Bio-hydrogen production by different operational modes of dark and photo-fermentation: An overview". International Journal of Hydrogen Energy. Vol. 36, Issue 13, pp. 7443-7459. 2011.

[2] P. Sinha and A. Pandey. "An evaluative report and challenges for fermentative biohydrogen production". International Journal of Hydrogen Energy. Vol. 36, Issue 13, pp. 7460-7478. 2011.

[3] K.Y. Show, D.J. Lee and J.S. Chang. "Bioreactor and process design for biohydrogen production". Bioresource Technology. Vol. 102, Issue 18, pp. 85248533. 2011.

[4] P. Hallenbeck and D. Ghosh. "Advances in fermentative biohydrogen production: The way forward?". Trends in Biotechnology. Vol. 27, Issue 5, pp. 287-297. 2009.

W.M. Chen, Z.J. Tseng, K.S. Lee and J.S. Chang. "Fermentative hydrogen production with Clostridium butyricum CGS5 isolated from anaerobic sewage slugde". International Journal of Hydrogen Energy. Vol. 30, Issue 10, pp. 1063-1070. August, 2005.

[6] X. Liu, Y. Zhu and S.T. Yang. "Butyric acid and hydrogen production by Clostridium tyrobutyricum ATCC 25755 and mutants". Enzyme and Microbial Technology. Vol. 38, Issue 3-4, pp. 521-528. February, 2006.

[7] J.H. Shin, J.H Yoon, E.K. Ahn, M.S. Kim, S.J. Sim and T.H. Park. "Fermentative hydrogen production by the newly isolated Enterobacter asburiae SNU-1". International Journal of Hydrogen Energy. Vol. 32, Issue 2, pp. 192-199. February, 2007.

[8] H. Jayasinghearachchi, P.M. Sarma, S. Singh, A. Aginihotri, A.K. Mandal and B. Lal. "Fermentative hydrogen production by two novel strain of Enterobacter aerogenes 
HGN-2 and HT 34 isolated from sea buried crude oil pipelines". International Journal of Hydrogen Energy. Vol. 34, Issue 17, pp. 7197-7207. September, 2009.

[9] C. Long, J. Cui, Z. Liu, Y. Liu, M. Long and Z. Hu. "Statistical optimization of fermentative hydrogen production from xylose by newly isolated Enterobacter sp. CN1". International Journal of Hydrogen Energy. Vol. 35, Issue 13, pp. 6657-6664. July, 2010.

[10] T.Zhang, H. Liu and H.H. Fang. "Biohydrogen production from starch in wastewater under thermophilic condition". Journal of Enviromental Management. Vol. 69, pp. 149156. 2003.

[11] H.S. Shin, J.H. Youn and S.H. Kim. "Hydrogen production from food waste in anaerobic mesophilic and thermophilic acidogenesis". International Journal of Hydrogen Energy. Vol. 29, Issue 13, pp. 1355-1363. October, 2004.

[12] A. Cakir, S. Ozmihci and F. Kargi. "Comparison of bio-hydrogen production from hydrolyzed wheat starch by mesophilic and thermophilic dark fermentation". International Journal of Hydrogen Energy. Vol. 35, Issue 24, pp. 13214-13218. December, 2010.

[13] S.Y.Wu, C.N. Lin and J.S. Chang. "Hydrogen production with immobilized sewage sludge in three-phase fluidized-bed bioreactors". Biotechnology Progress. Vol. $19 \mathrm{~N}^{\mathrm{o}} 3$, pp. 828-832. 2003.

[14] I. Ntaikou, G. Antonopoulou and G. Lyberatos. "Biohydrogen production from biomass and wastes via dark fermentation: A review". Waste Biomass Valorization. Vol. $1 \mathrm{~N}^{\circ} 1$, pp. 21-39. 2010.

[15] D.L. Valentine, D.C. Blanton and W.S. Reeburgh. "Hydrogen production by methanogens under low-hydrogen conditions". Archives of Microbiology. Vol. $174 \mathrm{~N}^{\mathrm{o}}$ 6, pp. 415-421. 2000.

[16] J.J. Lay, Y.J. Lee and T. Noike. "Feasibility of biological hydrogen production from organic fraction of municipal solid waste". Water Research. Vol. 33, Issue 11, pp. 2579-2586. 1999.

[17] C.Y. Chen, M.H. Yang, K.L. Yeh, C.H. Liu and J.S. Chang. "Biohydrogen production using sequential two-stage dark and photo fermentation processes". International Journal of Hydrogen Energy. Vol. 33, pp. 4755-4762. 2008.

[18] V. Gadhamshetty, Y. Arudchelvam, N. Nirmalakhandan and D.C. Johnson. "Modeling dark fermentation for biohydrogen production: ADM1-based model vs. Gompertz model". International Journal of Hydrogen Energy. Vol. 35, Issue 2, pp. 479-490. January, 2010.

[19] P.R. Jones. "Improving fermentative biomass-derive $\mathrm{H}_{2}$-production by engineering microbial metabolism". International Journal of Hydrogen Energy. Vol. 33, Issue 19, pp. 5122-5130. October, 2008.

[20] K. Uyeda and J.C. Rabinowitz. "PyruvateFerredoxin Oxidoreductase: IV. Studies on the reaction mechanism". Journal of Biological Chemistry. Vol. $246 \mathrm{~N}^{\circ} 10$, pp. 3120-3125. 1971.

[21] J. Wang and W. Wan. "Factor influencing fermentative hydrogen production: A review". International Journal of Hydrogen Energy. Vol. 34, Issue 2, pp. 799-811. January, 2009.

[22] C. Li and H. Fang. "Inhibition of heavy metals on fermentative hydrogen production by granular sludge". Chemosphere. Vol. 67 $\mathrm{N}^{\mathrm{o}}$ 4, pp. 668-673. 2007.

[23] J. Wang. "Comparation of different preteatment methods for enriching hydrogen-producing bacteria from digested sludge". International Journal of Hydrogen Energy. Vol. 33, Issue 12 pp. 2934-2941. June, 2008.

[24] A. Bisaillon, J. Turcot and P.C. Hallenbeck. "The effect of nutrient limitation on hydrogen production by batch cultures of Escherichia coli". International Journal of Hydrogen Energy. Vol. 31, Issue 11, pp. 1504-1508. September, 2006.

[25] C.Y. Lin and C.H. Lay. "A nutrient formulation for fermentative hydrogen production using anaerobic sewage sluge microflora". International Journal of Hydrogen Energy. Vol. 30, Issue 3, pp. 285-292. March, 2005.

[26] J. Wang and W. Wan. "Effect of $\mathrm{Fe}^{2+}$ concentration on fermentative hydrogen production by mixed cultures". International Journal of Hydrogen Energy. Vol. 33, Issue 4, pp. 1215-1220. February, 2008.

[27] M. Nakamura, H. Kanbe and J. Matsumoto. "Fundamental studies on hydrogen production 
in the acid-formig phase and its bacteria in anaerobic treatment processes-the effects of solids retention time". Water Science and Technology. Vol. 28, Issue 7, pp. 81-88. 1993.

[28] Y. Ueno, T. Kawai, S. Sato, S. Otsuka and M. Morimoto. "Biological production of hydrogen from cellulose by natural anaerobic microflora". Journal of Fermentation and Bioengineering. Vol. 79, Issue 4, pp. 395397. 1995.

[29] Y. Ueno, S. Otsuka and M. Morimoto. "Hydrogen production from industrial wastewater by anaerobic microflora in chemostat culture". Journal of Fermentation and Bioengineering. Vol. 82, Issue 2, pp. 194197. 1996.

[30] A.J. Guwy, F.R. Hawkes, D.L. Hawkes and A.G. Rozzi. "Hydrogen production in a high rate fluidised bed anaerobic digester". Water Research. Vol. 31, Issue 6, pp. 1291-1298. 1997.

[31] O. Mizuno, R. Dinsdale, F.R. Hawkes and D.L. Hawkes. "Enhacement of hydrogen production from glucose by nitrogen gas sparging". Bioresource Technology. Vol. 73, Issue 1, pp. 59-65. May, 2000.

[32] C.C. Chen, C.Y. Lin and J.S. Chang. "Kinetics of hydrogen production with continuos anaerobic cultures utilizing sucrose as the limiting substrate". Applied Microbiology and Biotechnology. Vol. 57 Nos 1-2, pp. 56-64. 2001.

[33] Y. Joon, T. Miyahara and T. Noike. "Effect of iron concentration on hydrogen fermentation". Bioresource Technology. Vol. 80, pp. 227231. 2001.

[34] B.E. Logan, S.E. Oh, I.S. Kim and S. Van Ginkel. "Biological hydrogen production measured in batch anaerobic respirometers". Enviromental Science and Technology. Vol. $36 \mathrm{~N}^{\circ}$ 11, pp. 2530-2535. 2002.

[35] J.S. Chang, K.S. Lee and P.J. Lin. "Biohydrogen production with fixed-bed bioreactors". International Journal of Hydrogen Energy. Vol. 27, Issues 11-12, pp. 1167-1174. 2002.

[36] C.C. Chen and C.Y. Lin. "Using sucrose as a substrate in an anaerobic hydrogen-producing reactor". Advances in Enviromental Research. Vol. 7, Issue 3, pp. 695-699. May, 2003.
[37] Y.K. Oh, E.H. Seol, J.R. Kim and S. Park. "Fermentative biohydrogen production by a new chemoheterotrophic bacterium Citrobacter sp. Y19”. International Journal of Hydrogen Energy. Vol. 28, Issue 12, pp. 1353-1359. December, 2003.

[38] S. Kumar, W.H. Chen, L. Li and S. Sung. "Biological hydrogen production: effects of $\mathrm{pH}$ and intermediate products". International Journal of Hydrogen Energy. Vol. 29, Issue 11, pp. 1123-1131. 2004.

[39] M. Ferchichi, E. Crabbe, G.H. Gil, W. Hintz and A. Almadidy. "Influence of initial $\mathrm{pH}$ on hydrogen production from cheese whey". Journal of Biotechnology. Vol. $120 \mathrm{~N}^{\mathrm{o}} 4$, pp. 402-409. 2005.

[40] H. Fang, C. Lin and T. Zhang. "Acidophilic biohydrogen production from rice slurry". International Journal of Hydrogen Energy. Vol. 31, Issue 6, pp. 683-692. May, 2006.

[41] C.H. Chou, C.W. Wang, C.C. Huang and J.J. Lay. "Pilot study of the influence of stirring and $\mathrm{pH}$ on anaerobes convering high-solid organic wastes to hydrogen". International Journal of Hydrogen Energy. Vol. 33, Issue 5, pp. 1550-1558. 2008.

[42] J.A.C. Leite, B.S. Fernandes, E. Pozzi, M. Barboza and M. Zaiat. "Application of an anaerobic packed-bed bioreactor for the production of hydrogen and organic acids". International Journal of Hydrogen Energy. Vol. 33, Issue 2, pp. 579-586. January, 2008.

[43] B. Soares, G. Peixoto, F.R. Albrecht, N.K. Saavedra del Aguila and M. Zaiat. "Potential to produce biohydrogen from various wastewaters". Energy for Sustainable Development. Vol. 14, Issue 2, pp. 143-148. June, 2010.

[44] S.I. Maintinguer, B. Fernandes, I.C.S. Duarte, N.K. Saavedra, M.A.T. Adorno and M.B.A. Varesche. "Fermentative hydrogen production with xylose by Clostridium and Klebsiella species in anaerobic batch reactors". International Journal of Hydrogen Energy. Vol. 36, Issue 21, pp. 13508-13517. October, 2011.

[45] A. Fangkum and A. Reungsang. "Biohydrogen production from sugarcane bagasse hydrolysate by elephant dung: Effects of initial $\mathrm{pH}$ and substrate concentration". International Journal of Hydrogen Energy. Vol. 36, Issue 14, pp. 8687-8696. July, 2011. 